\title{
РЕВІТАЛІЗАЦІЯ БУДІВЕЛЬ ТА СПОРУД ІЗ ЗАСТОСУВАННЯМ ОДНОПОЯСНИХ СІТЧАСТИХ МЕТАЛЕВИХ КУПОЛІВ ТА ОСОБЛИВІСТЬ їХ РОБОТИ
}

\section{REVITALIZATION OF BUILDINGS AND STRUCTURES USING SINGLE-LAYER MESH METAL DOMES AND THE PECULIARITY OF THEIR WORK}

Коломійчук Г.П., к.т.н., доцент, Майстренко О.Ф., к.т.н., доцент, Коломійчук В.Г., аспірант, Коломійчук В.Г., магістр (Одеська державна академія будівництва та архітектури, м. Одеса)

Kolomiychuk G.P., PhD., associate professor, Maistrenko O.F., PhD., associate professor, Kolomiichuk V.G., postgraduate student, Kolomiichuk V.G., master (Odessa State Academy Civil Engineering and Architecture, Odessa)

У світовій практиці будівництва широке розповсюдження знаходить ревіталізація будівель $і$ споруд з використанням пологих однопоясних сітчастих металевих куполів. Пологі куполи дозволяють утворювати менший будівельний об'єм, але їх робота під дією навантаження значно ускладнюється. I на сьогодні не достатньо вирішені проблеми розрахунку стійкості таких куполів.

During the revitalization, a set of works is carried out, providing for the preservation of the architectural appearance of buildings with the creation of internal filling and interiors and engineering and technological equipment in accordance with modern standards and requirements. In world practice, there are many unique examples that clearly demonstrate the specifics of these works with the use of metal domes. The effectiveness of dome coverings is known, but there are still unresolved issues that are partially considered in this work.

Examples of revitalization of buildings and structures using metal domes of coatings include: - a glass cone over a shot tower in Melbourne; - a glass dome with a mirrored cone and ramps in the revived Reichstag in Berlin; - glass domes over the gas meters in Vienna; - The glass dome of the Takamatsu Marugamecho shopping area in Japan; - the dome over the bullring in Khetiv.

Most often, shallow metal mesh domes are used in construction practice. Such structures make it possible to form a smaller building volume, but their work becomes much more complicated under the action of a load. And to date, the problems of calculating the stability of such domes have not been sufficiently resolved. The main reason is the discrepancy between the experimental data and the performed calculations. The actual shape and position of the mesh dome nodes, as well as its real stress-strain state during operation differs from the state developed by the project. The accumulated deviations of the dome geometry during its installation, manufacturing defects and 
damage received during operation significantly change the ideal design scheme used in the calculations and increase the probability of buckling.

The impossibility of erecting such structures with ideal geometric parameters due to errors arising from objective reasons is noted. These errors lead to the complication of the connection of the mounting structural elements of the domes in the nodes.

It is shown how large the differences in assessing the safety of a structure can arise if the standard deviation of a random variable responsible for the imperfection of the arrangement of nodes is incorrectly estimated.

Reliable unloading analysis is vital to ensure that the large span structure is reliably loaded into its design position. Potential failure caused by manufacturing defects and local effects such as defective welding and bolting can be detected and prevented in advance.

Research on the progressive destruction of spatial structures is not enough. The main reason for this: it is intuitively believed that spatial structures have a large number of duplicate elements and the ability to redistribute efforts. However, it has been demonstrated that failure of some critical elements can lead to progressive destruction of spatial structures.

To obtain the relationship between the critical load of buckling and the amplitude of the initial imperfections, the known results of experimental studies were used, where the accuracy was high in measuring imperfections and in carrying out loading of spherical shells. The obtained dependence allows introducing corrections for the value of the critical load of buckling of mesh domes, where the following is used as the initial data: - reduced dome thickness; - the largest amplitude of the measured initial imperfections of the shape after the erection of the structure at the construction site.

Ключові слова: ревіталізація, однопоясний сітчастий металевий купол, дефекти при виготовленні, недосконалості форми, стійкість.

Keywords: revitalization, single-layer mesh metal dome, manufacturing defects, shape imperfection, stability.

Вступ. Під час ревіталізації виконується комплекс робіт, що передбачає збереження архітектурного образу будівель, відповідно до сучасних норм та вимог. У світовій практиці $є$ багато унікальних прикладів, котрі наглядно демонструють специфіку вказаних робіт із застосуванням металевих куполів. Ефективність купольних покриттів відома, але є ще невирішені питання, які частково розглядаються в даній роботі.

Аналіз останніх досліджень та публікацій. Визначною пам'яткою Мельбурну є дроболиварна вежа - Шот Tауер (Shot Tower). Вона була побудована в 1890 році і оточена складами. Під час розвитку Мельбурна, інші будівлі знесені, але історично значуща 50-метрова Shot Tower збережена i була покрита 77-метровим конічним скляним куполом торгового центру Melbourne Central [1]. Скляний купол - найбільша конструкція такого типу у світі (рис. 1). Його діаметр 80 м, важить 490 т.

Купол відродженого Рейхстагу - чудова напівсфера (рис. 2), створена 3 міцного скла та металу - своєрідна тераса діаметром 40 м та висотою 
23,5 м [2]. Один пандус усередині купола призначений для підйому, інший - для спуску. Протяжність спіралі - 230 м, ширина - 1,8 м. Загальна вага купола становить 1200 т, а площа скляної поверхні - близько $3000 \mathrm{~m}^{2}$. На даху, у куполі, одночасно перебуває тисяча людей. Під його вершиною оглядовий майданчик, звідки відкривається кругова панорама Берліну. Купол улаштований так, що відвідувач бачить не лише панораму міста, а й залу засідань парламенту. Сучасний купол - частина екоенергосистеми будівлі. В середині нього - конус із 360 дзеркал у 30 рядів. 3 їхньою допомогою до зали парламенту потрапляе денне світло. Комп'ютерна програма регулює нахил дзеркал так, щоб за будь-якої погоди створювалося ідеальне освітлення. Гігантська лійка-конус забезпечує вентиляцію будинку взимку 3 мінімальними втратами тепла. Архітектор Норман Фостер на основі старої величної споруди створив зручний простір для роботи парламенту, зберігши історичні риси.

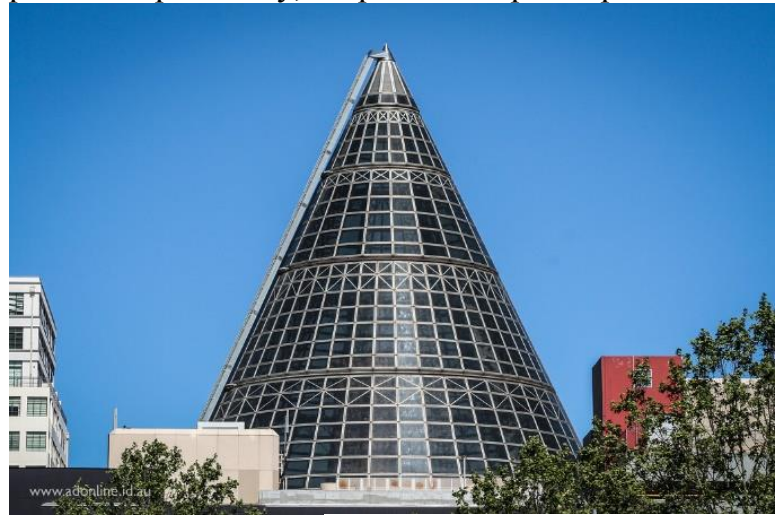

Рис. 1. Скляний купол над дроболиварною вежею в Мельбурні

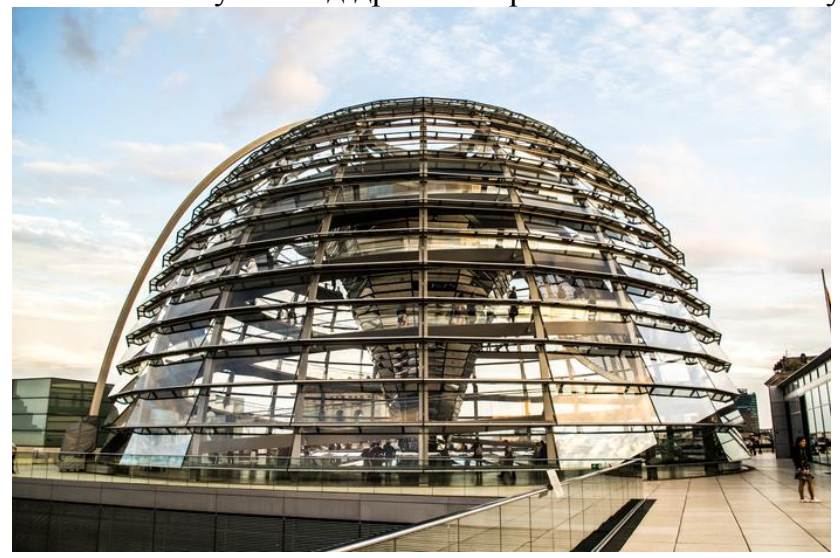

Рис. 2. Скляний купол над Рейхстагом у Берліні 
Унікальним прикладом $є$ ревіталізація промислових споруд газосховищ (газгольдерів) в місті Відні (Австрія) для громадського призначення (рис. 3). Газгольдери представляють собою чотири циліндричні споруди обсягом близько 90,0 тис. м³, висотою 70 м та перетином 60 м, кожна [3]. Навкруги так званого «мокрого» газгольдера влаштовані цегляні стіни. Вказані споруди були збудовані в 1896-1899 роках. У 1984 році вони перестали експлуатуватися.

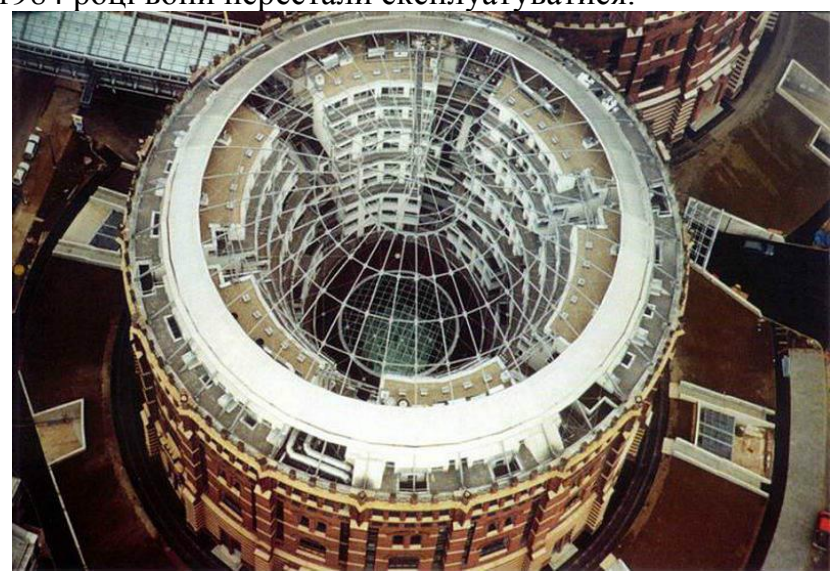

Рис. 3. Скляний купол над газометром у Відні

Визначною пам'яткою відродженого торгового району Такамацу Маругамематі $€$ новаторський дизайн простору круглої площі, вкритої величезним кришталевим куполом [4]. Купол збудований влітку 2007 року, має діаметр 26 м і висоту 32 м, що робить його найбільшим у Японії (рис. 4).

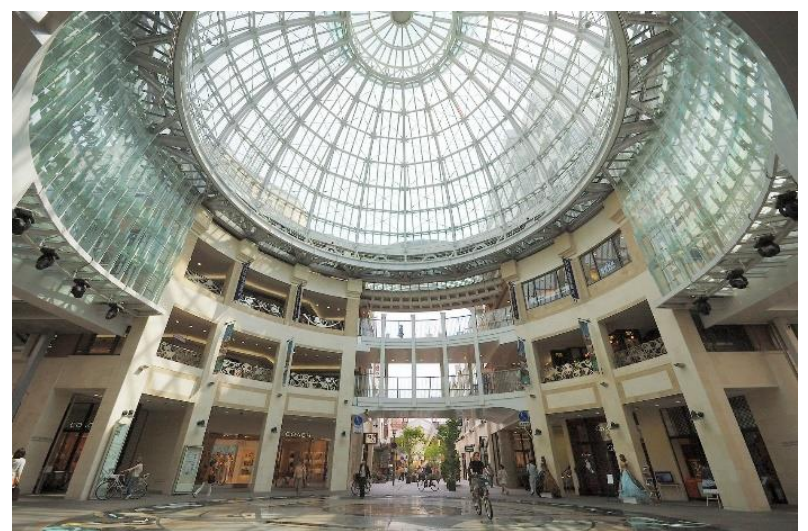

Рис. 4. Скляний купол торгової площі Такамацу Маругамечо 
В Хатіві (Іспанія) виконано ревіталізацію арени для бою биків 3 улаштуванням покриття над трибунами у вигляді металевого куполу (рис. 5). Оболонка покриття зведена за допомогою нового способу «Pantadome System» [5]. Купол сферичної форми з центральним отвором діаметром 42 м і зовнішнім діаметром 101,6 м, опертий на 44 колони, розподілених по колу діаметром 86,4 м.

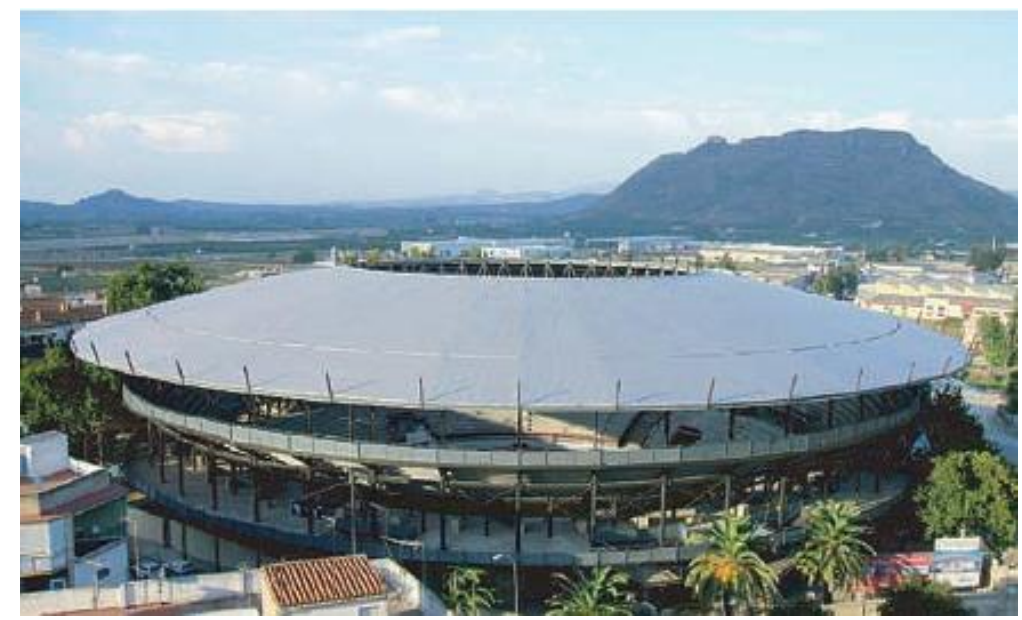

Рис. 5. Ревіталізована арена для бою биків у Хатіві

Цілі і завдання. Виконати аналіз нових досліджень по застосуванню однопоясних сітчастих куполів в ревіталізації будівель і споруд.

Основна частина. Купол - найбільш раціональне покриття в будівлях та спорудах круглої форми. Найчастіше в практиці будівництва застосовуються пологі металеві сіткові куполи. Такі конструкції дозволяють утворювати менший будівельний об'єм, але їх робота під дією навантаження значно ускладнюється. I на сьогодні недостатньо вирішені проблеми розрахунку стійкості таких куполів. Основною причиною $є$ розбіжність між експериментальними даними та виконаними розрахунками. Дійсна форма та положення вузлів сіткового купола, а також його реальний напружено-деформований стан у процесі експлуатації відрізняється від стану, розробленого проектом. Накопичені відхилення геометрії купола під час його монтажу, дефекти при виготовленні та пошкодження, отримані під час експлуатації, значно змінюють ідеальну розрахункову схему, що використана в розрахунках, $\mathrm{i}$ збільшують ймовірність втрати стійкості.

У роботі [6] на основі аналізу процесу зведення двопоясних металевих куполів показано причини появи початкових зусиль у елементах купола. Вказано на необхідність використання при монтажі підгоночних 
операцій, що супроводжуються силовими впливами та призводять до появи початкових зусиль через похибки. Запропоновано та підтверджено розрахунками конкретного куполу методику комп'ютерного моделювання силового усунення можливих похибок його монтажу.

У роботі [7] виконана спроба оцінити вплив недосконалості розташування вузлів на надійність купола. Аналіз стосується однопоясного сталевого сіткового купола, який дуже чутливий до прориву вузла. Траекторію навантаження-переміщення конструкції визначали за допомогою програми MCE-Krata. Для визначення ймовірності відмови, індексу надійності та індексу еластичності застосовано метод апроксимації методу надійності першого порядку. Аналіз надійності проводився за допомогою програмного забезпечення Numpress Explore, розробленого в Інституті фундаментальних технологічних досліджень Польської академії наук у Варшаві. У цій роботі показано, наскільки великі відмінності в оцінці безпеки конструкції можуть виникнути, якщо неправильно оцінити стандартне відхилення випадкової величини, що відповідає за недосконалість розташування вузлів.

Більшість збудованих сітчастих оболонок характеризуються одним або декількома вільними краями, які виникають в результаті обрізання опорної поверхні сітчастої оболонки, щоб забезпечити доступ до будівлі або інтегрувати сітчасту оболонку в існуючі конструкції [8]. Досі лише кілька наукових систематичних досліджень було присвячено впливу пружних граничних структур на стійкість сітчастих оболонок. Дане дослідження спрямоване на заповнення деяких прогалин у цій проблемі. Для цього проаналізована ідеальна гібридна одношарова сітчаста оболонка 3 вільним краєм та неактивним вигином. Чутливість сітчастої оболонки до згинальної жорсткості граничної арки та до зсуву жорсткості гратчастої оболонки досліджена за допомогою параметричного аналізу, який був виконаний з використанням чисельних експериментів.

При проектуванні покриттів із великим прольотом традиційний метод проектування стикається 3 багатьма труднощами, такими як невизначеність ефективної довжини вигину [9]. Виявлено, що проведено недостатньо роботи з аналізу розвантаження конструкцій під час зведення. Надійний аналіз розвантаження є життєво важливим, щоб забезпечити надійне навантаження великопролітної конструкції до свого проектного положення. Потенційний збій, спричинений дефектами виробництва та місцевими ефектами, такими як дефектне зварювання та болтове кріплення, можна завчасно виявити та запобігти йому. Ризик руйнування великопролітної конструкції можна усунути. Напругу фіксації можна звести до мінімуму, щоб уникнути потенційних збитків та пошкодження постійної конструкції. Запропоновано прогресивний синхронізований метод розвантаження для великопролітних конструкцій під час процесу зведення. 
У статті [10] описуються експерименти та аналіз повної поведінки неглибоких геодезичних гратчастих куполів після втрати стійкості. Хоча окремі елементи є прямими, їх геометричне розташування наближається до вигнутої поверхні, а типова поведінка сильно нелінійна, включаючи можливість раптових стрибків, при яких може відбуватися кілька переривчастих поштовхів від рівноважної одної конфігурації до іншої. Ряд неглибоких куполів було виготовлено за допомогою 3D-принтера та протестовано з використанням датчика навантаження та лазерного датчика наближення. На відміну від більшості попередніх досліджень, замість шарнірних або напівтвердих з'єднань, досліджувані решітки включають з'єднання, що передають момент, і фіксовані граничні умови по периметру. Таким чином, вигин є домінуючим видом деформації при бічному навантаженні, і на практиці можливі пов'язані моделі нестійкості. Повна залежність навантаження від усунення і множинні рівноважні конфігурації демонструються як у експерименті, так і у моделюванні. Експериментальні дані показують тісну кореляцію з нелінійним аналізом кінцевих елементів за допомогою методів відстеження шляху. Подано типові характеристики поздовжнього вигину елемента та його вплив на критичне навантаження. Зроблено висновки щодо симетрії та геометричної чутливості.

Хоча конструкції спроектовані так, щоб бути симетричними, їхня симетрія порушується незабаром після початкової лінійної стадії. Як правило, спочатку асиметричним стає внутрішній шестикутник, а потім зовнішні трикутники. Як і очікувалося, в експерименті спостерігається значна асиметрія. Приблизний кут разом із модальними зміщеннями використовується як міра асиметрії. Обидва результати добре узгоджуються з чисельним прогнозом.

Найглибший купол (структура С) показує дуже хорошу відповідність між чисельними та експериментальними результатами як якісно, так i кількісно. У той час, як для найдрібнішого купола (структура А) згода між експериментом та моделюванням менш вражаюча. Варто відзначити, що в експерименті є ряд чутливостей, крім загальних геометричних недоліків, наприклад, невелика невизначеність модуля Юнга, невелика зміна геометрії поперечного перерізу, можливість сповзання і плинність матеріалу при високих навантаженнях.

Аварії прогресуючого обвалення однопоясних сітчастих куполів серйозно загрожують громадській та соціальній безпеці. Структурна цілісність та здатність протистояти поступовому руйнуванню стають важливими вимогами при проектуванні конструкцій. Kiewitt Lamella i геодезичні однопоясні сітчасті куполи типові для куполів, що використовуються у великих громадських об'єктах. У роботі [11] проведено експериментальне дослідження та чисельне моделювання, щоб зрозуміти механізм перерозподілу внутрішніх сил під час прогресуючого обвалення куполів. Визначено та перевірено три ефективні методи оцінки 
опору прогресуючому обваленню та критичного зміщення. Результати показують, що і купол Kiewitt Lamella, і геодезичний купол зазнають проривного обвалення. Обвалення купола Kiewitt Lamella було викликане несподіваною локальною нестабільністю навколо елементів початкового руйнування, тоді як обвалення геодезичного купола було результатом швидкої зміни вузлового зміщення та різкого зниження жорсткості конструкції.

Прогресуюче обвалення - це поширення початкового локального руйнування від елемента до елемента, що в кінцевому підсумку призводить до обвалення всієї конструкції або непропорційно великої іiі частини. В останні роки повідомлялося про деякі серйозні аварії 3 прогресуючим обваленням конструкцій, викликані землетрусами, екстремальними погодними умовами або терактами. В результаті були проведені всебічні дослідження для вивчення здатності цих структур чинити опір прогресуючому руйнуванню. Досліджень прогресуючого руйнування просторових структур мало. Основною причиною цього $\epsilon$ така: інтуїтивно вважається, що просторові конструкції мають велику кількість дублюючих елементів та здатність до перерозподілу зусиль. Однак, було продемонстровано, що відмова деяких критичних елементів може призвести до прогресуючого руйнування просторових конструкцій. Оскільки просторові споруди зазвичай служать громадськими об'єктами, їхня здатність протистояти руйнуванню безпосередньо пов'язана 3 суспільною безпекою та соціальним забезпеченням. Отже, існує гостра потреба у подальших дослідженнях механізму прогресуючого обвалення просторових конструкцій.

Теорія тонкостінних оболонок є одним з найбільш детально вивчених розділів механіки. Однак, незважаючи на їі рівень опрацювання, в даний час ще залишаються невирішені проблеми. Однією з них є проблема, яка полягає у відсутності достатнього обгрунтування причин розбіжності теоретично і експериментально знайдених критичних навантажень втрати стійкості для тонкостінних оболонок.

Виходячи зі складнощів досліджень стійкості, для побудови залежності між критичним навантаженням втрати стійкості та амплітудою початкових недосконалостей і використання ії в інженерних розрахунках сітчастих куполів, було обрано такий підхід [12]. На геометрію виготовленого сферичного куполу вводяться обмеження на амплітуду початкових недосконалостей. В якості таких обмежень можуть бути використані допуски відхилень геометрії на виконання будівельномонтажних робіт. Для отримання залежності між критичним навантаженням втрати стійкості та амплітудою початкових недосконалостей використані відомі результати експериментальних досліджень наведених вище авторів, а також ті, де була висока точність у вимірах недосконалостей та в проведенні навантаження сферичних 
оболонок. Отримана залежність, що дозволяє вводити поправки на величину критичного навантаження втрати стійкості сітчастих куполів, де в якості вихідних даних використовується приведена товщина купола, найбільша амплітуда виміряних початкових недосконалостей форми після зведення конструкції на будівельному майданчику.

Висновки i перспективи досліджень. Наведено приклади ефективного застосування металевих куполів в ревіталізації будівель і споруд. Розглянуті причини, які викликають значну розбіжність між проектними розробками та побудованими просторовими конструкціями, а також роботи, що направлені на зближення цих розбіжностей.

Можна зробити висновок, що розглянута досить складна проблема, яка є актуальною і потребує подальшого вивчення.

\section{References}

1. Melbourne Central's Heritage [Electronic resource]. - Access mode: URL : https://www.melbournecentral.com.au/visitor-info/our-heritage

2. Zdaniye Reykhstaga v Berline [Elektronnyy resurs]. - Rezhim dostupa: URL : https://architectureguru.ru/reichstag-building-in-berlin/

3. Gasometer Town Vienna, Austria. Apartment complexes built into huge repurposed natural gas tanks. [Electronic resource]. - Access mode: URL : https://www.atlasobscura.com/places/gasometer-town

4. Kupol torhovoyi vulytsi Takamatsu Maruhamecho [Elektronnyy resurs]. Rezhym dostupu : URL : https://www.projectdesign.jp/201503/pn-kagawa/001997.php

5. Lazaro C. Detailing and construction of the pantadome roof structure for a bullring in Xativa (Spain) / C. Lazaro, A. Domingo // International Journal of Space Structures, 2010. - Vol. 25. - No. 4. - P. 229-241. DOI: 10.1260 / 0266-3511.25.4.229

6. Lebed E.V. Nachalnыe usylyia v dvukhpoiasnыkh metallycheskykh kupolakh yz-za pohreshnostei yzghotovlenyia y montazha ykh konstruktsyi / E.V. Lebed, A.A. Hryhorian // Vestnyk MHSU, 2015. - № 4. - S. 69-79.

7. Zabojszcza, Paweł \& Radoń, Urszula. (2019). The Impact of Node Location Imperfections on the Reliability of Single-Layer Steel Domes. Applied Sciences. 9. 2742. 10.3390/app9132742.

8. Fiammetta Venuti, Luca Bruno, Influence of in-plane and out-of-plane stiffness on the stability of free-edge gridshells: A parametric analysis, Thin-Walled Structures, Volume 131, 2018, Pages 755-768, https://doi.org/10.1016/j.tws.2018.07.019.

9. Y P Liu, S J Pan, Simon W K Leung \& S L Chan (2018) Design and construction of long-span single-layer dome structures by direct analysis, HKIE Transactions, 25:1, 29-43, DOI: 10.1080/1023697X.2017.1409663

10. Yue Guan, Lawrence N. Virgin, Daniel Helm, Structural behavior of shallow geodesic lattice domes, International Journal of Solids and Structures, Volume 155, 2018, Pages 225-239, https://doi.org/10.1016/j.ijsolstr.2018.07.022. 
11. xu, Ying \& Han, Qing-Hua \& Parke, G.A.R. \& Liu, Y.-M. (2017). Experimental Study and Numerical Simulation of the Progressive Collapse Resistance of Single-Layer Latticed Domes. Journal of Structural Engineering (United States). 143. 10.1061/(ASCE)ST.1943-541X.0001868.

12. Kolomiichuk H.P. Stiikist metalevykh odnopoiasnykh sitchastykh kupoliv z pochatkovymy nedoskonalostiamy / H.P. Kolomiichuk // Suchasni budivelni konstruktsii z metalu ta derevyny. - Odesa: ODABA, 2019. - Vypusk №23. - S.42-50.

\section{Список використаних джерел}

1. Melbourne Central's Heritage [Electronic resource]. - Access mode: URL : https://www.melbournecentral.com.au/visitor-info/our-heritage

2. Здание Рейхстага в Берлине [Электронный ресурс]. - Режим доступа: URL : https://architectureguru.ru/reichstag-building-in-berlin/

3. Gasometer Town Vienna, Austria. Apartment complexes built into huge repurposed natural gas tanks. [Electronic resource]. - Access mode: URL : https://www.atlasobscura.com/places/gasometer-town

4. Купол торгової вулиці Такамацу Маругамечо [Електронний ресурс]. Режим доступу : URL : https://www.projectdesign.jp/201503/pn-kagawa/001997.php

5. Lazaro C. Detailing and construction of the pantadome roof structure for a bullring in Xativa (Spain) / C. Lazaro, A. Domingo // International Journal of Space Structures, 2010. - Vol. 25. - No. 4. - P. 229-241. DOI: 10.1260 / 0266-3511.25.4.229

6. Лебедь Е.В. Начальные усилия в двухпоясных металлических куполах изза погрешностей изготовления и монтажа их конструкций / Е.В. Лебедь, А.А. Григорян // Вестник МГСУ, 2015. - № 4. - С. 69-79.

7. Zabojszcza, Paweł \& Radoń, Urszula. (2019). The Impact of Node Location Imperfections on the Reliability of Single-Layer Steel Domes. Applied Sciences. 9. 2742. 10.3390/app9132742.

8. Fiammetta Venuti, Luca Bruno, Influence of in-plane and out-of-plane stiffness on the stability of free-edge gridshells: A parametric analysis, Thin-Walled Structures, Volume 131, 2018, Pages 755-768, https://doi.org/10.1016/j.tws.2018.07.019.

9. Y P Liu, S J Pan, Simon W K Leung \& S L Chan (2018) Design and construction of long-span single-layer dome structures by direct analysis, HKIE Transactions, 25:1, 29-43, DOI: 10.1080/1023697X.2017.1409663

10. Yue Guan, Lawrence N. Virgin, Daniel Helm, Structural behavior of shallow geodesic lattice domes, International Journal of Solids and Structures, Volume 155, 2018, Pages 225-239, https://doi.org/10.1016/j.ijsolstr.2018.07.022.

11. xu, Ying \& Han, Qing-Hua \& Parke, G.A.R. \& Liu, Y.-M. (2017). Experimental Study and Numerical Simulation of the Progressive Collapse Resistance of Single-Layer Latticed Domes. Journal of Structural Engineering (United States). 143. 10.1061/(ASCE)ST.1943-541X.0001868.

12. Коломійчук Г.П. Стійкість металевих однопоясних сітчастих куполів 3 початковими недосконалостями / Г.П. Коломійчук // Сучасні будівельні конструкції з металу та деревини. - Одеса: ОДАБА, 2019. - Випуск №23. - С. 4250, doi:10.31650/2707-3068-2019-23-42-50. 